\title{
Etnohistoria de la sexualidad Misak: continuidades en los cambios y transformaciones
}

\section{Nancy Motta González}

\section{Resumen}

Este artículo analiza los cambios en las construcciones identitarias femeninas contemporáneas - desde el ámbito de las sexualidades - de mujeres indígenas de la etnia Misak del resguardo de Guambía. El texto pretende acercarse al mundo de la sexualidad, de la percepción de lo que es ser mujer y hombre desde distintas posiciones etáreas y generacionales entre los y las indígenas Misak, en el campo de la cultura, que debe de ser vista desde una perspectiva totalizante. A partir de 14 entrevistas en profundidad (12 mujeres y 2 hombres) y trabajo de campo intensivo en el resguardo, además del procesamiento especializado de los datos del censo 2005, se hace un análisis en dos direcciones combinadas: los procesos de subjetivación femenina en relación con la experiencia vivida en el pasado y en el presente de la sexualidad de las mujeres, y los cambios que ya se observan a través de los indicadores sociodemográficos entre la población.

Palabras claves: sexualidad, género, etnicidad e identidad, territorio.

\begin{abstract}
This article analyzes the changes in contemporary female identity constructions from the field of sexuality - of indigenous women from the Misak ethnic of the Guambía reservation. The text aims to approach the world of sexuality, perception of what is to be women and men from different positions between indigenous and Misak, in the field of culture, which should be viewed from a totalizing perspective. From 14 in-depth interviews (12 women and 2 men) and intensive field work in the shelter, in addition to the specialized processing of 2005 census data, an analysis is made in two directions: first, the processes of female subjectivity in relation with experience in the past and present of women's sexuality and the changes already observed by socio-demographic indicators among the population.
\end{abstract}

Keywords: sexuality, gender, ethnicity and identity, territory.

\footnotetext{
* Artículo tipo 1: de investigación científica según Colciencias. Se inscribe como parte de los resultados del proyecto de investigación Colciencias-Cidse/Región-Universidad del Valle, "Sexualidades y feminidades contemporáneas de mujeres blanco-mestizas, negras e indígenas: un análisis de cohorte generacional y étnico-racial".

Antropóloga, Magíster en Desarrollo Rural. Profesora Departamento de Historia, Facultad de Humanidades, Universidad del Valle. Actualmente jefa del mismo departamento. Miembro del grupo de investigación Asociación de Estudios Regionales-Región del Depto de Historia, clasificado como A1 por COLCIENCIAS y miembro del Centro de Estudios de Género, Mujer y Sociedad de la Facultad de Humanidades. Email: namogon@univalle.edu.co.
} 


\section{Introducción}

Desde hace un par de décadas en Colombia como en muchos lugares de América Latina, estamos asistiendo a la consolidación de una nueva manera de entender la diferencia étnica. En este país, los cambios son demandados por quiénes históricamente habían sido llamados indios o indígenas y ahora se revindican como Misak, Nasas, Kogis, Wayuus, Waunanas, Emberas, Awas, Uwas, etc., buscando revertir la exclusión y subordinación mediante su reconocimiento como Pueblo. El multiculturalismo colombiano expresado en su Constitución de 1991 ha conllevado a que las múltiples etnias presentes en el país empiecen generar un movimiento de revalorización de sus identidades y a establecer estrategias políticas de reetnización, teniendo en cuenta los cambios sociales, económicos, políticos y culturales.

Para el movimiento indígena en Colombia (ONIC), el colonialismo ha creado un ser indígena desvalorizado, condición que limita sus luchas por la liberación. Como una forma de revertir esas significaciones han trabajado por construir una identidad colectiva y aglutinadora alrededor de revindicar el término indígena por los propios nombres de sus etnias, que en este caso para la presente investigación constituyen los misak llamados por el colonialismo guambianos; se trata de una definición relativamente nueva en la larga historia de los indígenas y su relación con las y los colombianos.

Así, el ser Misak, actualmente va asociado a una propuesta de cambio en la forma de cómo se concibe al ser indígena, la diferencia étnica y las formas políticas de regirlas en el contexto nacional colombiano. Ser Misak se asocia con el derecho a despojarse de una identidad impuesta y estigmatizada (Ser Guambiano) para exigir y asumir una identidad positiva como base para las reivindicaciones étnicas.

Desde allí hablan de respetar y rescatar su cultura. La identidad y la cultura conllevan a las nociones de ser mujer y ser hombre en la etnia y cultura misak y al tema de las sexualidades. Hablar de sexualidad si bien no es un tabú cerrado hoy en día, las reflexiones al respecto se elaboran de manera selectiva según quien pregunta o indaga o el grado de intimidad en las relaciones de amistad que se han construido entres las y los sujetos sociales.

¿Porqué hablar de la sexualidad indígena, la trayectoria reproductiva, los roles femeninos y masculinos? Las Naciones Unidas (1995) plantea la necesidad de considerar el desarrollo de las poblaciones centrado en los individuos mismos, en sus necesidades básicas a satisfacer. Igualmente al considerar a la mujer como sujeto de atención para el desarrollo, consideró la posición de la mujer indígena en

el desarrollo de los pueblos, teniendo presente las especificidades de cada grupo étnico.

Los y las indígenas tienen una visión característica y de suma importancia entre las relaciones de población y desarrollo que suelen diferir de las de 
poblaciones con las que viven dentro de las fronteras nacionales". (Naciones Unidas, 1995:13)

Igualmente los programas de desarrollo deben estar orientados "aumentar el acceso de la población a la información, la educación, a los servicios de salud en general y de salud reproductiva de alta calidad. (Ibid: 9).

La fecundidad de la mujer indígena, su sexualidad, sus roles, la construcción de feminidad está en relación con la dinámica cultural de su grupo étnico, y desde una perspectiva de género. Hace parte de sus ordenamientos simbólicos y se hallan regulados por un complejo sistema de principios y normas, que con la educación-información recibida, la migración y las actividades económicas del grupo o fuera del grupo, nos señalan los cambios y permanencias, rupturas 0 persistencias de lo que es ser mujer o varón entre los y las indígenas.

En la presente investigación, analizaremos el territorio Wampia o Guambía y cómo su población: los misak, conciben la sexualidad ubicada en la feminidad y en la virilidad en su estructura social, que grados de mutabilidad, movilidad y transformaciones se han dado a través del tiempo. Existe un proceso de permanencia y otro de cambio. El primero nos remite a la tradición, el segundo a la adaptación o adecuación de la estructura social misak a las prácticas de la contemporaneidad. Diacronía y sincronía indispensable para entender el fenómeno socio-cultural de la sexualidad en este espacio étnico.

Metodológicamente para el análisis de la sexualidad indígena misak se entrevistaron a 12 mujeres y dos hombres en el año 2008 en el territorio de Guambía. Las entrevistas e historias de vida, permitieron visualizar roles tanto femeninos como masculinos que admiten relacionar elementos cotidianos y conductas en el ejercicio de su socialización y empoderamiento dentro del espacio privado, en articulación con su construcción de identidades femeninas y masculinas.

\section{Espacio, tiempo y cultura Misak}

La historia guambiana es una historia de agua. Nace de muy alto, de los páramos y de Pishimisak y baja hasta llegar al valle."

Taita Avelino Dagua

El resguardo de Guambía actual se encuentra ubicado en la jurisdicción del Municipio de Silvia -Departamento del Cauca. Sus límites son: al norte con el resguardo de Pitayó; al sur con el municipio de Totoró y el área urbana de Silvia; al oriente con los resguardos de Mosoco y Yaquivá de la etnia nasa; al occidente con los resguardos de Quizgó y la zona urbana de Silvia. 
El territorio guambiano denominado Wampia por los namui misak está surcado a cada trecho por innumerables corrientes de agua. El agua rige la vida guambiana: en la agricultura, en la cultura y en la historia; sus recorridos y sus seres constituyen el hilo conductor que estructura y enlaza toda la cosmovisión del pueblo misak. Es en este espacio que los guambianos se consideran a sí mismos los hijos del agua y del arco iris. (Dagua H. Avelino, Tunubalá, Gerardo, et. al, 2002:19).

El territorio namui misak cuenta con una población de 23.462 habitantes en un espacio de 23.694 hectáreas. La población guambiana se encuentra en tercer lugar demográfico en la región del Suroccidente colombiano; el primer lugar lo ocupa la etnia nasa, el segundo lugar corresponde a los pastos en Nariño y el cuarto lugar la etnia yanacona en el Cauca, habitantes del Macizo Colombiano.

Los orígenes del pueblo guambiano o misak empiezan con la pareja: uno se llama Kallin y el otro Pishimisak. El Kallin es el taita o sur en quién se centra la autoridad, el trabajo, la organización de las mingas y el conocimiento de todas las variedades de plantas presentes en el territorio. Es el equilibrio y la armonía para el pueblo misak; Pishimisak constituye el cordón umbilical entre las lagunas macho y hembra, es la mama Dominga que vive entre las plantas del páramo y a la vez madre de las aguas del territorio guambiano. Ambos seres él (Kallín) y ella (Pishimisak) son los grandes conocedores del territorio y de la cosmovisión misak y son los encargados de aprender, enseñar y poblar todo el Gran Territorio. (Dagua, Aranda, Vasco, 1998: 25).

El agua y el fuego rige la vida guambiana: en la agricultura, en la cultura y en la historia; sus recorridos y sus seres constituyen el hilo conductor que estructura y enlaza toda la cosmovisión del pueblo misak. La sexualidad, la paternidad, la maternidad, el hombre y la mujer, la fecundidad, forman parte de este orden simbólico y sus imaginarios se hallan regulados por un sistema complejo de principios y normas parentales que se estructuran en el grupo étnico.

Esta cosmovisión es muy importante porque la sociedad misak maneja una dualidad en el espacio, en el tiempo y en la gente. La relación de pareja entonces es muy fuerte para el proceso de socialización de los hijos e hijas en la construcción de la identidad misak. El niño aprende con su padre el mundo de lo masculino, arar la tierra conocer los ciclos agrícolas, conocer las plantas medicinales y el saber pensar para dirigir el cabildo después, son las prácticas paradigmáticas del ser varón misak . La construcción de la virilidad misak se sustenta en el trabajo real, físico, y en lo que eso significa en la estructura del sujeto. (Dagua, Aranda, Vasco, 1998:131).

La niña se la orienta al mundo doméstico y a la casa como su lugar de privilegio y en donde debe hacerse mujer. La madre debe de enseñar a la hija a ser mujer y una ishuk misak se caracteriza por ser trabajadora, responsable en la 
educación de las hijas y de los hijos, para lograr una pervivencia y re-existencia ${ }^{1}$ de la vida del territorio wampia.

En la cosmovisión misak esta dicotomía de actividades de las y los niños no se ven de manera excluyente y de oposición sino de manera complementaria, (Correa, F, 1981: 32, y Villa Posse, 1985: 27).

Desde una perspectiva de género, las mujeres indígenas con cosmovisiones duales (culturas aymarás, quechuas y mayas ) ven la equidad de género "dentro de la complementariedad armónica de hombre y mujer, no dentro de una autonomía de género o superioridad de un sexo sobre otro" (Calfio, M Margarita y Velasco Luisa Fernanda, 2005:3).

La siguiente cita nos señala tal complementariedad:

Allí nos trataban por igual, mi papá mi mamá nos trataban por igual, eso si he sentido no nos tenían preferencias....¿En mi casa? Si pues si ósea teníamos que ayudar entre todos, mi mamá nos enseñaba pues todos por igual y eso también pues, me a servido mucho y yo quiero enseñarles lo mismo a mi hijo (Ascensión, mujer Misak, campesina clase media baja, 44 años, docente, educación secundaria, casada con tres hijos, La Campaña).

\section{Formación de la ishuk misak}

El centro de la educación misak lo constituye el na chack - cocina- y más específicamente el nak kuk - el fogón o candela- , en torno a él o ella (fogón, candela) giran y se relacionan los miembros de la familia; es allí donde se enseña y se aprenden las tradiciones del pueblo misak y desde donde se desarrolla el todo. Barbara Muelas (1993: 6) ha dicho "el derecho nace en las cocinas" y se refiere al muy complejo proceso de interacción verbal que encierra y transmite los contenidos de la identidad, ya que simboliza el vínculo del territorio y desde donde se nutre el ideal de ser misak. Al nacer se entierra el ombligo del o la infante al lado derecho del fogón y seguirá atado al espacio doméstico, unido por ese hilo invisible así se aleje espacial y temporalmente. (Muelas, 1993:2).

En el proceso de socialización, las madres misak han llevado a sus espaldas a sus hijos hasta los 14 meses. Los cargan en todo momento, ya sea que cocine, cuide los animales, realice tareas agrícolas, asista a reuniones o ceremonias, ella no se desprende de su hijo sea varón o mujer. Para la mujer misak, el hijo o la hija es parte real y física de sí misma. (Pachón, 1987; Cabildo de la parcialidad de Guambía, 1980).

\footnotetext{
${ }^{1}$ Concepto acuñado por el pueblo Misak que aplica a diferenciar del concepto resistir ya que este sugiere un enfrentamiento hacia el otro. Entre tanto re-existencia alude a que ya se existe y se lucha para seguir existiendo.
} 
Cuando aprende a caminar el universo del niño y de la niña cambia. De la espalda de la madre en la cual ha permanecido más de un año, pasa a mirar de frente el universo doméstico. En adelante, la educación será tanto de los mismos padres como del cuidado de los hermanos mayores y especialmente de las hermanas y/o de algún familiar cercano cuando llegue la hora de ir a la escuela.

Umh mas o menos desde los seis años, como hasta los 16 años, viví mucho tiempo con él [el abuelo], hasta que me vine a estudiar acá a Silvia y cuando vine a estudiar a aquí en el pueblo ya mis papás arrendaron una piecita, yo empecé a vivir ahí en la piecita donde mis papás arrendaron. Al principio me arrendaron donde una tía, ella también se murió yo viví con ella también bastante tiempo, ¿Como unos qué? Unos dos añitos vivía ahí con mi tía y luego me arrendaron en otra parte y ahí fue donde yo termine el bachillerato. (Narcisa, 32 años, en unión libre, una hija, bachiller, docente, Cacique).

Los niños y las niñas guambianas al acercarse a la escuela a recibir su instrucción formal también sin ninguna división sexual del trabajo reciben instrucción en las labores agrícolas y de las actividades domésticas pues significa cuidar la tierra. Como a la tierra hay que fecundarla para que germine la vida y de los frutos, pero el lugar de la casa también hay que cuidarla, hombres y mujeres deben de trabajar la tierra, y deben de mantener la casa, es Kallín y Pishimisak juntos. (Dagua, Aranda, Vasco.1998: 45). Paralelo a esta actividad este grupo étnico también ha privilegiado en sus hijos e hijas la educación formal como nos lo informa Sandra:

Entonces me fui a vivir allá con mi tía, o sea en Piendamó, en eso hice mi primaria que fue en la escuela, cercana ahí de la vereda, luego fui hacer mi bachillerato que fue en Pescador. Pase luego fui a estudiar en Popayán otros dos años enfermmería auxiliar (Sandra, misak, 22 años, soltera, profesional, enfermera).

La construcción de la feminidad lo constituye el reino del tejido, el saber hilar es la actividad exclusiva de la mujer. La importancia del tejido en las mujeres es que ellas "van tejiendo la vida de la sociedad guambiana y acompañando su reproducción” (Dagua, Aranda, Vasco, 1998: 62). Luisa, una estudiante universitaria guambiana residente en Cali nos informa:

No pues, mi mamá dice que... desde que uno ya tenga conciencia y que ya sepa... pueda hacer algo? Siempre nos empieza es a enseñar a tejer ya que como desde niña, supuestamente, bueno ellos desde niños siempre han empezado con eso mis abuelitos como eran más exigentes, siempre ellos tenían que... a los cinco o seis años levantarse temprano y hacer sus cosas ir a ordeñar o levantarse hacer el desayuno y si están así haciendo nada, hacer, tejer, hacer cualquier cosas así ¿artesanías? Igual siempre ella me ha exigido en esa parte también, como le han exigido a ella que tengo que tengo que estar haciendo cosas que estoy así, desocupada, hacer jigras o hilar y también si mi papá... si mi mamá está ocupada y mi papá se va a trabajar yo tengo que ir a acompañarlo para ir hacer el desayuno, el desayuno digo, el almuerzo 
ayudarle a trabajar en lo que se pueda y así siempre me he dedicado a eso.

(Luisa, 20 años, soltera, estudiante universitaria Barrio Meléndez, Cali).

Con relación a la pubertad, se tienen unos códigos simbólicos en las niñas puesto que ya se preparan para ser mujeres, es un rito de paso importante en el pasado, pero, que hoy ha ido perdiendo su importancia ya que ha dejado de verse como crisis vital y se incorporado en la educación formal. No se tiene la idea de la adolescencia como ocurre en la sociedad occidental. En los rituales del refrescamiento, la niña debe estar encerrada, hilando cuatro puchos de lana y tejiendo cuatro mochilas. (Villa Posse, 1967: 40) Un ritual de refrescamiento se enuncia aquí en la voz de una de nuestras entrevistadas:

si cuando venia la primera menstruación teníamos que decírselo a ella que ella nos iba a hacer un ritual y así fue nosotros teníamos más confianza con la abuelita y le dijimos entonces nos hacia un baño he a mí me vino la primera menstruación como a los catorce quince años, entonces le dije yo ya estaba acá en el colegio, ella ya me había recomendado eso que si no me hacia ese remedio entonces habían mujeres que tenían mal olor, entonces pues yo fui allá donde mi abuelita y ella consiguió todas las plantas que se requiere para hacer ese baño y preparo una comida especial me acuerdo tanto era sopa de maíz tostado le echo todas las cosa que da en clima frió pues, olluco, arveja, papita y ella me mando a repartir a mi tenía unos invitados unos peones de ahí cerca de la casa y me mando a repartir el almuerzo a mi ese era el ritual y también empezó una mochila hacer una jigra y me mando hacer una jigra tocaba hacer cuatro en ese tiempo y botarlas al rió. Pero pues en ese tiempo creo que ya se habían perdido algunos valores porque a mí no me mando a botar al rió sino que me mando a terminar la mochilita pequeñita y aprendí hacer la mochila. Pues es como crecer, es como el cambio de mujer a niña de niña a ser mujer y de realizar los trabajos más duritos, de aprender a hacer los trabajos de mujer misak. (Rosa, 32 años, en unión libre, una hija, bachiller, docente, Cacique).

La preparación de la menarquia ocurría en la casa o también en la escuela y en ambas circunstancias les realizaban el ritual. Las púberes asumen la responsabilidad de trabajar la tierra en las faenas agrícolas y en las del hogar. La información sobre la educación y la sexualidad se sustenta en el aprendizaje de las tareas que por tradición competen a la mujer; porque sabiéndolo la niña llegará a ser misak-misak o ishuk misak, y por ende reconocida como futura esposa y madre. Para las mujeres mayores, la primera menstruación es vivida con naturalidad y las mujeres cercanas se encargan de orientar a la joven, pero es principalmente la madre o la abuela quién se encargaba de dar la información sobre como desenvolverse. Para las hoy mujeres jóvenes, representa el paso a otra etapa de su crecimiento y al manejo de su sexualidad.

La madre o la abuela velan porque la niña cumpla con los rituales del trabajo: - tierra, cocina e hilado -, se introduzca en la ruta de la feminidad cuyas actividades claramente definidas son la esposedad y la maternidad. La feminidad se estructura en torno a éstas actividades, que la niña debe de aprender 
mediante el proceso de iniciación por la madre o parientes (abuelos/as, tíos/as, hermanas) hasta que se logre un dominio sobre el espacio del que se volverá dueña y señora- ishuk misak. Se trata de un dominio privativo de la mujer, y en la medida que se centra en la casa, debe de proveerle los significados fundamentales que le definen su feminidad. (Villa, 1967: 29)

\section{El mundo laboral y del trabajo}

Ya hemos dicho que en la mujer misak, el mundo del trabajo es la huerta agrícola, el nak-kuk (fuego) y el hilar-tejido. En las y los guambianos, "la tierra constituye la fuente principal de subsistencia y su desarrollo trasciende no solo la vida cotidiana y su ciclo vital, sino la existencia misma de la comunidad" (Pachón, 1987: 237).

Como prácticas agrícolas tradicionales conservan la tumba y quema, la rotación de cultivos y barbecho, éste último con muchas dificultades hoy, pues con la escasez progresiva de tierras disponibles y el desgaste de la misma, la subsanan con la utilización de fertilizantes, por un lado, o por la compra de tierras en otros lugares del Cauca, ampliando y colonizando territorios, y también con la recuperación de tierras.

..... Yo viví con mis padres mi papá y mi mamá y... yo tuve un abuelito que él me quería mucho, y yo vi que yo me la pasaba siempre con él y... la recuperación de tierras en Santiago, (Narcisa, 32 años, en unión libre, una hija, bachiller, docente, Cacique).

La mujer misak tiene una amplia participación en las actividades de comercio de los productos de la finca y la huerta casera (agrícolas, pecuarios y piscícolas), comercio artesanal de su tejidos en las plazas de mercado de las cabeceras municipales y en ciudades como Popayán y Cali, lo que les genera ingresos y una mayor autonomía en el manejo de recursos.

Ir a cuidar una señora que había tenido un aborto. Me toco ir a trabajar como empleada, pero yo apenas tenía nueve escasos añitos. Igual sabía, la señora era muy amable. Entonces conseguí un trabajo en Armenia, y me fui para Armería a trabajar en unos supermercados; de mercaderista. En Armenia trabajé como año y medio de mercaderista. (Betty, 32 años, casada, cuatro hijos, primaria completa, ama de casa, Silvia).

La educación en las niñas guambianas les generó amplios horizontes laborales, como lo demuestran estos relatos:

Mi vida laboral, apenas culminó mi bachillerato en la normal, me fueron a buscar en Popayán, que necesitaban acá una docente para trabajar, me llevaron una carta, llegue acá, entonces me presente y fácil resulto el trabajo. (Rosa, 32 años, en unión libre, una hija, bachiller, docente, Cacique). 
Por otra parte, las mujeres misak emigradas a las ciudades, cuando no se encuentran en calidad de estudiantes, se articulan por medio del trabajo cuenta propia o al servicio doméstico. Tania nos plantea lo siguiente:

Después de estudiar, en una casa de familia haciendo oficio domésticos. En una casa en Bogotá, estuve para cuidar dos niños, uno tenía dos años y medio y el otro un año y medio, allí también el trato de los señores era bueno, bien pero no me gustaba, era, bueno yo sabía a lo que vine, pero no me gustaban los niños, no es que no me gusten si no que, como que los niños de la ciudad son muy cansones, entonces uno como que se cansa por todo y a las tres semanas me fui.

Luego estuve como operaria en una floristería en Bogotá y considero ese el trabajo más importante (Tania, 22 años, soltera, estudiante universitaria, Cali).

En términos de empleo, "la familia Guambiana, depende en un $88 \%$ de los ingresos proporcionados por la agricultura comercial de la Papa y un $7 \%$ de la ganadería en una pequeña proporción. Otro grupo muy pequeño, un 5\% depende de algunos ingresos como empleado del cabildo o en el magisterio Wampia o Misak, en los programas, en el hospital mama Dominga o en las empresas comunitarias, cooperativas y Proyectos Productivos y comerciales del Cabildo" (Velasco, 2008)

El relato de Pedro da cuenta de sus múltiples trabajos:

Mi vida laboral ha sido, auxiliar de cafetería de panadería, después pasé a un instituto católico, hasta ahora somos amigos con ese sacerdote, es una institución canadiense, se llama San Pio X y ahí trabaje como dos años, empecé como auxiliar de oficios varios, me mandaban a limpiar vidrios a barrer a trapear, entonces fueron dando confianza, confianza, confianza ya auxiliar de pronto de la impresora, de la imprenta de todas esas cosas que se manejan en las editoriales, de arrumar los papeles, de cortarlos, de usar la guillotina hasta que llegue a manejar la librería, una librería que vendía en ese tiempo hace ocho diez años atrás vendía... a diario millón, millón quinientos a diario de ganancia libre, entonces ahí aprendí a manejar la caja registradora, llevar cuentas a vender, como se vender los artículos más caros, como se promociona, como se entretiene a cliente para que por lo menos lleve algo, todas esa técnicas aprendí ahí (Pedro, 33 años, separado, bachiller, un hijo, trabajo comunitario resguardo Wampia).

\section{La familia Misak}

La institución familia ${ }^{2}$ es muy importante en Guambía porque se considera el centro de la cultura y de la educación. Se respeta a los mayores, no solo a los padres y la parentela sino también a los hermanos-as mayores denominados $<$ nutata> si es hijo mayor o <numama s si es hija mayor. Por lo tanto estos dos

\footnotetext{
${ }^{2}$ Eugenia Villa (1985) informa que la familia en Guambia es variada porque constituyen familias nucleares y extensas. Va ligada a las reglas del matrimonio y descendencia, a la residencia postmarital y a las relaciones de producción y de complementariedad en el trabajo de la pareja.
} 
apelativos son de carácter obligatorio para las y los hijos menores. Se les prohíbe decir sus nombres propios (trabajo de campo). Pedro continúa en la información:

Bueno yo, los primeros pinitos como se dice, los hice allá en la vereda Guambia Nueva porque hay dos hermanas que vivían allá pues ahorita vive una sola y yo me crié con la segunda de mis hermanas era como mi mamá, mi numama. (Pedro, 33 años, separado, un hijo, bachiller, realiza trabajo comunitario en Wampia).

La familia guambiana o misak se caracteriza por el predominio de hogares nucleares completos con hijos, tiende a favorecer el matrimonio católico y un menor peso porcentual, la unión libre. Entre los misak la institución del amaño período en el que la pareja joven convive por un tiempo sin hijos o con hijos - no se opone al matrimonio, ya que posteriormente la presión colectiva de los padres de ambos esposos y de la comunidad los lleva al matrimonio, sin embargo esta práctica se ha ido debilitando en las nuevas generaciones.

(...) no soy casada pero en unión libre, eso es igual la responsabilidad por que le toca hacer igual, ya sea casada o en unión libre, las cosas son iguales, el mismo oficio, el mismo trabajo y la misma responsabilidad aunque hay personas que dicen que casadas que, que rico que es mejor casadas, yo no pienso en eso a pesar que he tenido una educación tan moralista no, después de que uno respete y se haga respetar, es igual la responsabilidad y el cambio eh...en mi familia pues, como yo he... siempre me tenían tanta confianza en la casa lo asumieron eeeehh como con respeto. (Rosa. 37 años, unión libre, con una hija, bachiller normalista, docente en Silvia.)

El predominio en el parentesco afín es la monogamia con ritual católico o en unión libre y recientemente la monogamia seriada tanto en hombres como en mujeres. La estructura familiar misak es bilateral con residencia patrilocal postmatrimonio en primera instancia, lo que da origen a familia extensa. Luego se segmentan constituyendo familias nucleares estableciéndose los varones con sus esposas en viviendas independientes contiguas a las tierras de su padre, por tanto constituyen patrones residenciales neolocales virilocales de manera dispersa. En la fase de fisión, el reparto de tierras puede comenzar desde el casamiento de los hijos. Rige en la herencia un principio de igualdad masculina, sin embargo las mujeres aunque tengan hermanos varones, heredan siempre, lo que se constituye como la herencia residual. Todos los hijos-as al heredar, deben buscar tierras fuera del resguardo, por tanto han ido colonizando otros territorios del centro del departamento como Piendamó, Caldono y Morales.

Los misak residen en viviendas con patrón espacial disperso, el matrimonio es de carácter endogámico y exogámico entre las veredas, pues los matrimonios interraciales con mestizas-os no son avalados, aunque se dan, pero dicen no tienen las mismas costumbres. Veamos el testimonio de Pedro:

(...)empezaron las diferencias por ejemplo ella quería, ella me demostraba de muchas maneras que me quería, pero por ejemplo, como yo era líder, algunos 
mayores dirigentes acá no me aceptaban, o sea no aceptaban, no era tanto ese problema porque igual, la persona que iba a vivir era conmigo no con los taitas. Pero ahí empezaba como a dudar, en ese sentido y en mi familia también. Al comienzo fueron un poco cerradas decían por ejemplo no podía trabajar como una guambiana, no podía trabajar las artesanías como la guambiana, no podía madrugar como la guambiana todo lo que hacia la guambiana, por ahí empezaron. Yo también empecé como a escucharlos. (Pedro, 33 años, separado, un hijo, bachiller, realiza trabajo comunitario en el resguardo Wampia).

La poliginia puede darse en los líderes indígenas pero está mucho más controlada por la comunidad debido a la influencia histórica de larga duración de la Iglesia Católica y de otras iglesias en los últimos 30 años. No puede olvidarse que los guambianos tuvieron una mayor interacción con los poderes coloniales y la religiosidad católica está asociada a esa dominación colonial. Esto significa que se valora más la estabilidad de la pareja a lo largo de los distintos ciclos de vida, en tanto el madresolterismo tiene una eventual presencia. "Pues dentro de la casa me hicieron casar obligadamente (...). Pues ya teniendo hijos, cómo voy a dejar al marido, hasta ahora cumplo y hasta la muerte voy a cumplir, porque mi Dios nos da la vida, nos ha dado pa' criar (...)." Julia, 64 años, siete hijos, estudios de primaria, ama de casa, La Campana.

La influencia de la Iglesia Católica en el pueblo misak se refleja en la distinción fuerte que se hace entre hijos naturales - resultado de la unión libre - y los legítimos a través del matrimonio católico, teniendo los segundos el derecho de herencia de acuerdo a las normas y costumbres de la comunidad. Sin embargo, esta situación ha ido cambiando, de tal manera que tanto las y los hijos de matrimonio como las y los hijos de unión libre también heredan. En la existencia de la institución del amaño en muy pocas veredas del resguardo, se espera que la pareja se case, o sea, el amaño es un estado transitorio, donde el hombre puede devolver a la mujer si considera que no llena los requisitos según las prácticas tradicionales, ${ }^{3}$ pero después de casados la situación cambia, privilegiándose la estabilidad de la pareja y no es bien visto el abandono de la mujer por parte del hombre.

La soltería masculina y femenina en el orden familiar tradicional tampoco es bien vista en la población misak, pero en las nuevas generaciones hay dinámicas de cambio al pesar más el proyecto escolar, lo cual está incidiendo en una significativa disminución en las tasas de fecundidad. Al respecto Narcisa anota:

Cuando nosotros estábamos de novios, como a los tres años, él me dijo que si quería tener una relación sexual, entonces yo decía, 'nooo, yo no puedo, uno estudiando y que yo quede en embarazo, ¿usted qué hace?', era la pregunta que yo le hacía, entonces él me decía que no pasaba nada, que él respondía

\footnotetext{
${ }^{3}$ La institución del amaño ha perdido vigencia desde hace una década, con la educación formal en las nuevas generaciones, optando más bien por el matrimonio de manera directa o unión libre, con residencia neolocal, patrilocal o virilocal.
} 
por lo que iba a pasar (...). Entonces él me insistía y uno con esa duda, uno que no había terminado el bachillerato y con un hijo (...)." (Narcisa, 32 años, en unión libre, una hija, bachiller, docente, Cacique).

\section{Sexualidad y cambios en las percepciones sobre el cuerpo femenino}

La sexualidad en las poblaciones indígenas andinas en su conjunto aún está articulada a la función reproductiva. Es difícil observar todavía un comportamiento de procesos de individuación alrededor de la vivencia del placer en mujeres y hombres separado de la dinámica reproductiva. No aparece claramente visible la vivencia de la heterosexualidad explorando distintas alternativas de placer entre el hombre y la mujer en las áreas de resguardo. Según Cortés et al (op. Cit.: 39) los hombres y mujeres misak no se besan, "excepto entre los jóvenes más expuestos a la influencia externa", de acuerdo como lo anota Vicky:

Ahora que yo me pongo a recordar, cuando yo veo a los muchachos abrazados, besándose, yo me pongo a pensar que antes no era así, uno nunca sabía esa palabra de "mi amor", nada de eso, si no que era como si fuéramos dos amigos que se entendieran, no más, y cuando no peleábamos, era hablar bien. (Vicky, 37 años, casada, cuatro hijos, primaria completa, ama de casa, Silvia).

Esto también se corroboró en el trabajo de campo, especialmente entre las mujeres de mayor edad al relatar sus experiencias sexuales y las interacciones de afecto con sus maridos. La desnudez en el acto sexual entre las mujeres y hombres misak de resguardo no es aceptado y menos la masturbación clitorial y otras formas de placer del cuerpo femenino en interacción con el cuerpo masculino. A tenor de esta información, lo relevante es que el pudor aflora en todas las respuestas de las mujeres y hombres misak ${ }^{4}$. El mundo de la sexualidad es el mundo de la vida personal y colectiva, no es permisible pasar al campo del lenguaje. Una guambiana nos indica:

Nada, los indígenas todos son muy reservados y todo eso, lo vengo a descubrir ahora que otras familias que no son indígenas de donde yo soy hablan con mucha naturalidad de eso a las niñas, de la menstruación, de los besos, de las relaciones, de cuidarse, de los anticonceptivos o sea en otras familias yo veo que se manejó eso desde muy pequeña con la niña. A mí nunca se me dijo nada de la menstruación, el beso era fatal, un novio pues peor, o sea, muy distinto, nunca se volvió a hablar del tema jamás, a uno que le dicen es ino! (Aurora, 34 años, estudios técnicos de diseño de moda, casada, dos hijas, residente en Cali).

Para los guambianos -as el tema de la sexualidad y del cuerpo forma parte de aquello que la familia y los parientes informan a los pequeños-as y

\footnotetext{
${ }^{4}$ Advirtamos que el pudor no necesariamente tiene que ver con un modelo cultural de referencia "indígena". Entre otras razones porque fue un componente del proceso civilizatorio occidental. Ver al respecto Elías (1998: 407-450).
} 
adolescentes pero se mantiene en el campo de lo secreto y de lo sagrado, de ahí la dificultad de ventilarlo o expresarlo abiertamente. Veamos el siguiente ejemplo, en el que a pesar de que la entrevistada hace el esfuerzo por dar una respuesta en ningún momento logra entrar en detalles sobre su primera relación sexual:

[Bueno eh, ¿cómo fue esa primera vez con tu esposo? ¿Cómo él te dijo que quería estar contigo? ¿O si antes de eso el te tocaba el cuerpo? ¿Tú lo permitías? ¿Cómo empezó el ya a acceder a ti?] No sé cómo explicar (risa nerviosa), no se verdad, como explico eso jajá, jajá [¿Él qué te decía, que quería estar contigo, o simplemente pasaron las cosas sin decirse nada?] $\mathrm{Si}$ pues... eso después de que yo, espere primero pienso, después te digo. [Tranquila que eso no, solo yo lo escucho] No pues él me decía, como yo tuve relación antes de que yo fuera a vivir con él, pues, pues él me... yo no sé por lo que él me quería llevar a la casa yo no sé, para ya convivir con él pues yo no quería ir, porque yo decía jno! yo tengo que conseguir trabajo para estar más con mis papas yo decía, el decía no estaba el afanado, mas por juntarse conmigo y yo decía ay por ahorita no quiero, yo no quiero ser señora yo decía; yo todavía quiero vivir más tiempo, como yo estuve tanto tiempo allá en el colegio encerrado todo eso, pues yo quería estar así con mis papas al lado de mis papas, siempre me decían no que... siempre era pues que él quería que yo fuera ir a vivir con él. Yo no sé, fue en un tiempo que una vez, no sé, que de tanto exigirme pues me dijo... ah antes de eso pues mi esposo había tenido un hijo en otra señora y yo no me había dado cuenta, si no que él me dijo. Por eso también parecía que quería llevar y yo no me había dado cuenta, si no que cuando yo había llegado a la casa, esos problemas que llegaron que sí, que la otra muchacha que ya iba tener a la hija, todo eso y él por eso... yo pues entre mi pensé, después de que ya estuve allá es por eso no más, que esa muchacha también quería venir con mi esposo, yo creo que era por eso es que tanto afán de él y ya pues una vez ya me dijo: solamente yo no sé será porque uno es débil seria, yo no sé, no pensé nada y en esas pues no supe cómo fue que pasó la relación jah! de allí yo tanto, sufrí tanto ah, todo caso todo el embarazo yo lloré también, por que dije ¿para que yo hice relación? Yo, por ejemplo, tuve compañeros y nadie me decían cosas así, yo no sé yo pensaba así y mi abuela también me decía que usted cuando consiga novio no haga tocar de su cuerpo, que tenía que hacer respetar todo eso, pero ese día pues yo no, no sé, no supe cómo fue que paso la relación con él. (Ascensión, mujer misak, 44 años, docente, educación secundaria, casada con tres hijos, La Campaña).

Todavía entre las mujeres más jóvenes de los resguardos es posible que el tabú de la desnudez no haya cambiado demasiado. El relato de Pedro, muestra que el componente del pudor está presente aún hoy día en la relación sexual:

[¿Hasta qué edad te acuerdas de ver a tus hermanas desnudas?] No, para nosotros sea como mi mamá y mi papá, de mi familia creo que hasta yo soy chapado a la antigua como se dicen, y eso era algo muy, muy escondido, nos enseñaba muchas cosas pero del respeto, por ejemplo a las mujeres siempre inculcaban de cómo sentarse, de cómo tenía que comportarse en la familia y en la cocina entre el hermano y la hermana, los papas, pero nunca digamos lo que hoy se llama educación sexual, o sea que así se besa, así se enamora, eso nunca ni siquiera yo llegue a vivir, por ejemplo mis hermanas mis hermanos siempre me dicen "mira eh nos has enseñado a, si consigue un 
novio a mirar la personalidad quien quiera ser novio o novia para después que sea buena esposa o buen esposo", siempre nos has enseñado a eso eh... la familia de la persona, la responsabilidad, muchas cosas pero por ejemplo de hablar de órganos sexuales, hablar de... una relación así sexual nunca, entonces yo crecí con eso... (Pedro, hombre misak, 33 años, campesino clase baja, separado, un hijo, educación secundaria, trabajo comunitario, Santiago de Guambía).

Los adultos hablan de la sexualidad en sus reuniones colectivas, particularmente en las mingas, pero siempre desde el lado picaresco y jocoso. Por otra parte, el tema de la sexualidad se agota en las relaciones sexuales en tanto vivencia entre una mujer y un varón, pero se extiende, al mismo tiempo, a todas las relaciones que impliquen procreación: los animales y las plantas.

En sus relaciones, en los acercamientos amorosos y desde lo imperativo de las pulsiones y los deseos aprenden cosas dentro del circulo de compañeros-as en la escuela o colegio, en las fiestas, y de manera fáctica, o las nuevas generaciones de madres a sus hijas, como lo atestigua Aurora:

Y ahora con mi hija, hablamos de los besos, la niña se está tocando y yo la veo y ¿mami, usted que siente cuando se toca ahí? "No sé". Eso se llaman cosquillas, pero usted no debe meterse las manos ahí mami porque están sucias, se infecta, y la mando a buscar un cuco. Bueno, hablamos de los besos con ella y con mi hijo, hablamos de la sexualidad, o sea, ya viendo yo que, que es muy frecuente de que los muchachitos jóvenes embaracen las peladitas, entonces bueno hay que explicarle a ver, que es la sexualidad, que debe usar condón. O sea, reforzarles lo que les dicen en el colegio, con los padres, porque uno lo que se enteran es en la calle. Porque yo lo que me enteré de todo lo que tenía que ver con amor besos, sexualidad, métodos anticonceptivos, enfermedades venéreas todo eso no me entere fue en el colegio, jamás hable de eso con ellos. Entonces en la familia no había tema sexual, no se a que más se le puede llamar sexualidad, que habláramos nosotros pero de ese asunto no, de esos asunto jamás se trataron (Aurora, 34 años, casada, una hija, estudios técnicos de diseño de moda, residente en Cali).

El pudor aflora en todas las respuestas de las mujeres y hombres misak. El relato de Ascención nos indica lo siguiente:

(...)Y como así ver desnuda a mi mamá nunca porque somos más reservadas las indígenas, no es como nuestros hijos que andan así al aire, ni yo misma no me acuerdo, que me allá pasado eso, ni a mi mamá ni a mi papá no he visto así desnudos, son más conservados, así de esa forma, ni he sentido yo ni he observado eso en mi casa a ninguno. (Ascensión guambiana, 44 años, casada, con tres hijos, bachiller, docente en la vereda La Campana.). 
Sin embargo, es un hecho que se están dando importantes cambios en las generaciones de mujeres y hombres misak menores de 30-35 años en relación con sus vivencias alrededor de la sexualidad ${ }^{5}$, así como de sus percepciones. Esto se expresa en el testimonio de una mujer guambiana respecto a la clara evidencia de la presencia de hombres jóvenes con orientaciones sexuales no normativas dentro de sus comunidades:

Yo creía que eso era como producto de la degradación social que se estaba dando, el consumir muchos alimentos con inyecciones con hormonas, yo siempre había creído eso, pero ultimadamente también estoy viendo que dentro de la comunidad de nosotros, aquí los Guambianos, están resultando algunos jóvenes así, pues no es mucho pero hay unitos (...) (Bety, mujer misak, 32 años, casada, cuatro hijos, primaria completa, labores domésticas, Cali).

Las diferentes manifestaciones de la sexualidad en la población misak pasan entonces por fuertes controles en el espacio de la vida familiar. La figura del padre es mucho más dominante, garantizada por el peso de la influencia de la Iglesia Católica y el matrimonio; pero el espacio económico con el que juega la mujer alrededor del comercio de productos agrícolas, pecuarios, piscícolas y artesanales, pero también vía educación, el acceso a fuentes de trabajo con remuneración, le da más autonomía. En el caso del pueblo guambiano se combinan así mayores controles a la vida sexual de mujeres y hombres, pero a la vez opera una mayor autonomía económica de la mujer esposa, debido al tipo de división del trabajo con el relevante peso de la actividad comercial que realizan las mujeres.

Por otro lado, si bien no se puede excluir que haya expresiones individuales de sexualidades no normativas (homosexuales y bisexuales), ellas son silenciadas en las comunidades y en varias ocasiones son valoradas como un problema del mundo occidental y como tal de la sociedad mayor que no tiene que ver con las prácticas tradicionales indígenas. En este punto tampoco puede desconocerse la influencia de la Iglesia Católica y de las iglesias evangélicas que reprueban estas conductas. No obstante, es bastante probable que con los mayores niveles educativos de las mujeres y los hombres misak al interior de las comunidades del resguardo y en los sitios de residencia colonizados, sobre todo en las cabeceras

\footnotetext{
${ }^{5}$ Ya es más visible la presencia de hombres que eventualmente asumen roles femeninos, por ejemplo en la preparación de la comida para una minga, al lado de mujeres. También hombres que ocupan cargos de dirección en el Cabildo que conviven con otros hombres y otros que visitan en Cali espacios de sociabilidad homosexual. Estas expresiones de sexualidades no normativas observadas hasta el momento son masculinas. No se observó ni fue posible registrar un comportamiento de mujeres con sexualidades no normativas, pero esto tampoco se manifestó hasta el presente en las mujeres y hombres del resguardo. De cualquier forma, sobre los "nuevos" comportamientos masculinos misak no se hace presente todavía un registro explícito a través del lenguaje. Sin embargo, el ambiente de pudor en los resguardos guambianos ya no puede desconocer la presencia de conductas homoeróticas especialmente masculinas como se observó en la cita de Bety. Entre los misak a pesar que estas conductas sean calificadas, como más características de la cultura occidental, también comienza a aparecer un reconocimiento de su visibilidad.
} 
municipales, las sexualidades hetero más abiertas al placer corporal y las no normativas comiencen a tener espacios de tolerancia y respeto.

Ello se refleja según lo indica el Plan de vida misak (2007) en las menores tasas globales de fecundidad entre la población misak (por debajo de 3,7 hijos por mujer en edad fértil), a diferencia por ejemplo de las nasa (superiores a 4,2 hijos). La educación, la información y la autonomía de las mujeres misak han incidido. El siguiente testimonio de Vicky da cuenta del uso de anticonceptivos para espaciar el número de nacimientos:

Yo planifique durante 16 años y nunca tuve... o nunca he tenido problemas. Use el DIU o el espiral, hace un tiempito me lo hice retirar porque fui a una cita con el ginecólogo y me dijo que era bueno hacérmelo retirar un tiempito para que descansara porque ya había sido mucho tiempo con ese aparato y entonces que era bueno hacérmelo retirar, entonces hace un tiempito me lo hice retirar. (Vicky, 38 años, casada, cuatro hijos, primaria completa, ama de casa. Silvia.)

También en el resguardo se habla de que al conformar una pareja se tenga como máximo dos o tres hijos. Mary plantea:

Yo creo que como mujeres, habiendo esa posibilidad de no traer niños a sufrir, a pesar de que uno consiga la pareja, de no siempre que se tengan relaciones quedarse en embarazo. Por ejemplo, mi mamá fue la que me aconsejó para que planificara cuando tuve la primera niña, porque ella decía, 'en mis tiempos nunca, ¿cuando había eso?', y uno a veces no quería tener hijos y los esposos bravos, y lo obligaban a uno, quisiera o no quisiera, lo cogían a la fuerza y uno tenía que estar asumiendo otro hijo, año por año, y eso era muy difícil, sabiendo que no hay comida, tan dura que es la vida, y mi mamá decía que ella siempre le recalcaba eso a mi papá, y él como que no entendía, Y entonces dije, 'eso es cierto, uno cómo se va a llenar de hijos', y empecé a planificar, y hasta ahorita yo me he cuidado con eso (...)." (Mary, 32 años, casada, dos hijas, estudios universitarios, docente, Las Delicias).

Lo que se destaca es que las guambianas y las nuevas generaciones están desacralizando el ámbito de lo sexual y trabajando el marco de la salud reproductiva y de los afectos y mostrando nuevas maneras de vivir, y en términos misak de re-existir

Como se puede observar, la tradición misak se conjuga con nuevos modelos procedentes del mundo mestizo, vía - educación-, se han re-elaborado las prácticas culturales, y las nuevas generaciones lo que han hecho es enriquecerla y movilizarla. La modernidad ha implicado un cambio en los estilos de vida de los y las guambianas y de las representaciones sociales. Las y los adolescentes misak, no asumen nuevas posiciones ante la sexualidad porque ellas-os lo deciden, sino porque ya encontraron el terreno preparado, en alguna medida, por sus propios padres.

Los adultos-as de hoy (mayores de 40 años) cuando fueron adolescentes probablemente jamás llevaron a la comunidad una revista pornográfica, ni habrán 
pisado un cine de películas para adultos. Los adolescentes de hoy, mujeres y varones, no solamente que lo miran sino que, además, lo llevan a casa, a la escuela, al colegio. Los materiales pornográficos han empezado a formar parte de las rutas del saber de las nuevas generaciones misak. Así lo comenta Bety, "de pronto videos, a veces miramos videos de sexualidad o hemos asistido a terapias de pareja, que son muy espectaculares, así usted no tenga pareja. Es algo que usted va prendiendo".( Bety, 34 años, casada, cuatro hijos, primaria completa, ama de casa, Silvia)

Del goce como tal es imposible hablar con nuestras- os entrevistados, sin embargo si manifestaron la experiencia de la sexualidad vivida. El enamoramiento es cosa secreta, asegura la privacidad y, sobre todo, la libertad para el ejercicio de la sexualidad según lo comenta Aurora:

[Cómo es la sexualidad, como la manejaban ustedes] Yo la manejaba como algo que no debería enterarse nadie, nadie, nadie, ni siquiera una amiga, porque yo jamás le conté a mis amigas, qué día ni cuando me acosté con él, se vinieron a dar cuenta cuando me vieron embarazada. La sexualidad para mí era un secreto, un secreto que se vive entre la persona que a uno le gusta y uno y nadie más debe saberlo y habían límites, siempre hay uno de los dos que sabe más, o sea, en el caso mío, pues él era el que sabia más, nunca puede saber si lo había hecho con una persona antes y hasta después... que había hecho porque es muy reservado, jamás me lo contó. (Aurora, 34 años, casada, una hija, estudios técnicos de diseño de moda, residente en Cali.).

Después del enamoramiento se pasa al galanteo con o sin relación sexual y luego a la formación de la unión marital ritualizada o no. Mary nos cuenta al respecto lo siguiente:

[¿A qué edad tuviste tu primer acercamiento, ya digámoslo así más intimo con alguien?] Hum, pues yo creo que fue con mi esposo, porque... Yo lo conocí cuando estudiaba, estaba más o menos como en noveno, entonces siempre me lo encontraba por ahí cuando salía del colegio por la galería los martes, estaba por ahí parado y pues siempre... si, me silbaba me llamaba, así y después, creo que cuando ya estaba en décimo el entro a trabajar de docente, aquí al núcleo al colegio al ladito de donde yo vivía, de pronto eso fue como, como, si lo miráramos desde otra visión diríamos que, como si el destino, nos estuviera uniendo, entonces, el apareció aquí y... si se hizo amigo de mi hermana, ella estaba de profesora de danzas ahí, y luego me empezó a conocer a mí y nos fuimos haciendo amigos, nos invitaba así a diferentes cosas, que vamos a tomar un café, que la invito a esto lo otro, entonces a partir de eso fue que empezamos como a conocernos y si él, él es de las personas que... como él estuvo en un seminario y estuvo, era como reservado en esas propuestas, los hombres guambianos, creo que se caracterizan por ser simples, de una lo que quieren, y ya, no que le digan cosas a uno, entonces el me dijo no que... que si que él había estado interesado en mi y que, que le dijera si o no, de una sí o no, diga si o no para el desaparecerse. Entonces yo le dije que si, para ver cómo funcionaban las cosas y si, así 
empezamos a salir (Mary, 32 años, casada, dos hijos, estudios universitarios, docente, Las Delicias.)

El tema de la salud sexual y reproductiva empieza a cobrar importancia por el espaciamiento de los embarazos entre las mujeres misak menores de 30 años con niveles educativos secundarios. Esto permite que paulatinamente se valore la experiencia del placer sexual sin el riesgo de embarazo entre las mujeres con mayor escolaridad. Si bien las mujeres no tienen un reconocimiento en la esfera política, si lo tienen en los campos de la educación y de la salud reproductiva. Las mujeres misak tienen una importante participación en el Hospital Mamá Dominga de Silvia y ciertamente desde estos espacios pueden negociar mejor con el poder masculino. Esto lo reconoce un miembro del cabildo urbano de Cali:

La mujer es importante en los cambios que ha habido. Antes no tenía tanta importancia porque no había tanto estudio. Ahora hay mucho estudio, hay mucho trabajo, hay mucho que hacer en la comunidad, entonces hoy en día la mujer es más importante que el hombre. El hombre ha ido decayendo. La mujer ha ido subiendo. Por ejemplo, yo conozco a Bárbara Muelas, a Bárbara Morales, a María Elena Oyunuey [...] Antiguamente la mujer era para estar en la casa lavando la ropa, haciendo la comida, en sus quehaceres. Ahora ya no es así. A pesar de que todavía existe, porque el guambiano siempre ha sido machista [...] (Don José, hombre misak, 61 años, separado, dos hijos, miembro del cabildo urbano de Cali).

Sin embargo en la actualidad, debido al proceso educativo, las mujeres se han articulado a la vida sociocultural y política de la comunidad guambiana como alguaciles, secretarias, alcaldesas, educadoras y últimamente cargo de vicegobernadora en los resguardos, "cargos que han desempeñado responsable y éticamente" (Plan de vida, 2007).

"Ahora la mujer es compañera del hombre, ayuda a pensar, a hacer y tener de las cosas. La mujer es más fuerte y capaz de sobresalir frente a las adversidades de la vida”. (Plan de vida, 2007).

Lo que se muestra es que el mundo indígena misak es eminentemente femenino por cuanto su eje es la tierra, la madre de quién todos dependen. El imaginario identitario se ha construido con esta base y este se ha extendido también a los espacios urbanos a donde han llegado. La mujer indígena universitaria y profesional está empezando a transformar desde su identidad y desde sus pueblos, las relaciones que han signado los roles de la paternidad y maternidad. La recurrencia en las mujeres misak emigradas es que regresen al resguardo para integrarse a las actividades políticas del cabildo, o en el área de la docencia, otras en cambio se instalan definitivamente fuera de él, pero siguen manteniendo vínculos familiares y sociales con el resguardo. (Motta y Posso, 2007:170).

El cambio producido por la migración bien para estudiar o bien para trabajar, ha hecho que se adapten a las nuevas circunstancias, se articulen a los nuevos lugares, rurales o urbanos y continúen estableciendo marcadores identitarios tanto 
objetivos como subjetivos, principalmente en el nivel simbólico. (Motta y Posso, ibid). La migración de los misak ha supuesto cambios en la forma de asegurar la subsistencia: la base ya no está únicamente en la tierra, sino también en los ingresos que se obtienen a través de empleos o trabajos por cuenta propia, que realizan tanto hombres como mujeres, con lo que sus aportes se igualan simbólicamente. Esto permite mostrar que los roles domésticos de los y las misak, se adaptan, las formas de entender las responsabilidades, relaciones y derechos en el hogar cambian, dando lugar a nuevas relaciones que transforman el significado que antes se les otorgaba. (Bastos, Amigo Santiago, 2007: 124).

La re-existencia misak significa mantener el orden simbólico de la vida y la sexualidad, pero permitiendo cambios, transformaciones y redefiniciones a lo largo de la historia misak partiendo de las voces de la ishuc en los procesos socioculturales, económicos y políticos de la cual ha sido parte.

\section{BIBLIOGRAFÍA}

\section{Fuentes documentales}

Plan De Vida Misak. 2007 Guambía.

\section{Entrevistas}

Ascensión, mujer Misak, 44 años, docente, La Campaña.

Aurora, 34 años, estudios técnicos de diseño de moda, residente en Cali.

Betty, 32 años, ama de casa, Silvia.

José, hombre misak, 61 años, miembro del cabildo urbano de Cali.

Julia, 64 años, ama de casa, La Campana.

Luisa, 20 años, estudiante universitaria, Barrio Meléndez, Cali.

Mary, 32 años, docente, Las Delicias.

Narcisa, 32 años, docente, Cacique.

Pedro, 33 años, trabajo comunitario resguardo Wampia.

Rosa, 32 años, docente, Cacique.

Rosa, 37 años, docente en Silvia.

Tania, 22 años, estudiante universitaria, Cali. 
Vicky, 37 años, ama de casa, Silvia.

\section{Fuentes bibliográficas}

Bastos Amigo, Santiago. (2007) "Familia, género y cultura. Algunas propuestas para la comprensión de la dinámica de poder en los hogares populares" En Robichaux, David (Compilador) Familia y diversidad en América Latina. Estudios de caso. Clacso Libros. Buenos Aires.

Calfio M. Margarita, Velasco, Luisa F. (2005) Mujeres indígenas en América Latina: Brechas de género o de etnia. Seminario Internacional Pueblos Indígenas y afrodescendientes de América Latina y el Caribe: relevancia y pertinencia de la información sociodemográfica para políticas y programas. CEPAL, Santiago de Chile.

Cortés, P.; Suarez, T.; Prado, N.; Y García, W. (1989). Socialización del niño indígena. Popayán: Universidad del Cauca, Centro de Investigaciones y Servicios.

Correa, Francoise (1981) Espacio y territorio en la organización social Tawiana. s.e. (Rafi 023) Bogotá.

Dagua, Abelino, Tunubala, Gerardo, et al. (2002) La Voz de nuestros mayores. Colección Educativa PI UREK. Editorial López. Popayán.

Dagua, Abelino, Aranda, Misael Y Vasco, Luis Guillermo. (1998) Guambianos. Hijos del aroiris y del agua. Cerec, Los cuatro Elementos, Fondo promoción d ela cultura y Fundación Alejandro Escobar. Bogotá.

Elias, Norberto. (1998) La Civilización de los padres y otros ensayos. Grupo editorial Norma. Santafé de Bogotá.

Motta, G. Nancy, Posso, Jeanny. (2007) Hacia el reconocimiento de una identidad indígena urbana en Cali. Estudio etnológico de las comunidades indígenas ubicadas en el municipio Santiago de Cali: Kofan, Guambiana, Quichua, Inga, Yanacona y Nasa. Alcaldía santiago de Cali, Ministerio del Interior y de JusticiaDirección de Etnias, Fundación General de Apoyo a la Universidad del valle, Cali.

Muelas, Bárbara (1993) Relación Espacio-Tiempo en el pensamiento guambiano Trabajo presentado en la Maestría de Lingüística. Universidad del Valle. Cali

Organización De Naciones Unidas (1995) Proyecto de Plataforma de Acción IV Conferencia Mundial de la Mujer.

Pachon, Ximena. (1987) "Guambía" En Introducción a la Colombia Amerindia. Instituto colombiano de Antropología. Bogota 
Velasco, Nancy Jenny. (2008)Construcción de las identidades femeninas Misak. Informe presentado en la asignatura de Investigación. Maestría en Historia. Departamento de Historia Universidad del valle. Cali

Villa, Posse, Eugenia (1967) Aspectos generales de los guambianos y ciclo vital de la mujer Sin publicar. Mimeo

Villa Posse, Eugenia. (1985) Aspectos y Características de la Familia en el caso del indígena Guambiano Dpto del Cauca. Universitas Humanística, Pontificia Universidad. Javeriana. Facultad de Ciencias Sociales, Vol.-. 14 No.23 (Rafi No. 38) Bogotá.

Recibido: Octubre 14 de 2010

Aprobado: Mayo 9 de 2011 